\title{
Rapid casting technology based on selective laser sintering
}

\section{Li Yang, Shi-yan Tang, *Zi-tian Fan, Wen-ming Jiang, Xin-wang Liu}

State Key Laboratory of Materials Processing and Die \& Mould Technology, School of Materials Science and Engineering, Huazhong University of Science and Technology, Wuhan 430074, China

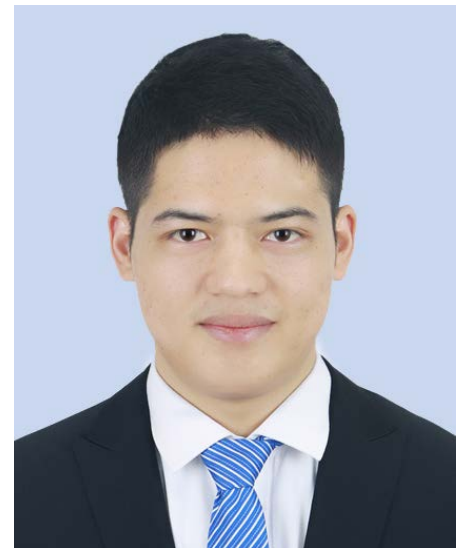

\section{Li Yang}

Ph.D, Postdoctoral Fellow (Huazhong University of Science and Technology). His research interests include rapid casting technology, and materials, technology and equipment of ceramic additive manufacturing. He has obtained the Postdoctoral Innovation Post Funding of Hubei Province, presided over one Innovation Fund of Huazhong University of Science and Technology, participated in one National Major Research \& Development Program of China and two National Natural Science Foundation of China. He has published 16 research papers in journals and conferences, and possesses three invention patents of China.

E-mail: yanglicl@hust.edu.cn

Corresponding author:

*Zi-tian Fan

E-mail: fanzt@hust.edu.cn

Received: 2021-05-17

Accepted: 2021-08-23
Abstract: Selective laser sintering (SLS), as a kind of additive manufacturing technology, which uses a laser beam to scan and heat powder material layer by layer to form parts (models), is widely used in the field of casting, mainly for preparing casting coated sand cores, investment casting patterns, etc. The SLS technique facilitates rapid casting and shortens the casting production periods by eliminating mold preparation. In this study, we reached conclusions for the basic principles and characteristics of SLS methods, and focused on the research status, key technology and development trend of SLS in the fields of forming coated sand-casting molds and investment casting patterns.

Key words: selective laser sintering; additive manufacturing; rapid casting; coated sand; investment casting pattern

CLC numbers: TG221; Document code: A; Article ID: 1672-6421 2021 04-296-11

\section{Introduction}

Selective laser sintering (SLS) technology adopts a high-power laser beam to selectively irradiate the surface of the target powder bed. The powders then are heated and sintered (i.e., interparticle fusion) for bulk joining. After one layer is completed, the platform will descend in an increment of one-layer thickness, and a new layer of powder is spread onto the previous surface for the next run of heating and joining, so that the 3D parts are stacked layer by layer, and finally the unfired powder is removed to obtain the parts ${ }^{[1]}$.

SLS was invented by Deckard and Beaman at the University of Texas at Austin, with the very first patent filed in $1986^{[2]}$, and was further developed by the DTM company. The first SLS equipment was developed in 1988. The Sinter Station 2000, a commercial production facility, was launched by 3D Systems Company in 1992. The Germany company EOS successively launched three series of SLS forming equipment in 1994. For decades, the University of Texas at Austin and the DTM company (3D Systems) in the United States performed a lot of research works in the SLS field, including equipment development, process and material development ${ }^{[3-4]}$.

Domestic research on SLS technology began in the 1990s. Beijing Longyuan AFS Co., Ltd. successfully developed the first AFS selective laser sintering machine in early 1995. The research group in Huazhong University of Science Technology (HUST) carried out the research and development of the SLS equipment system, and launched the commercial HK series powder sintering equipment ${ }^{[4]}$. Recently, the domestic institutions engaged in SLS technology research mainly include: HUST, Beijing University of Aeronautics and Astronautics, Nanjing University of Aeronautics and Astronautics, Dalian University of Technology, Southwest Jiaotong University, North University of China and other universities and research institutions ${ }^{[5]}$.

SLS technology plays an important role in manufacturing complex, lightweight, thinwalled parts, and developing new products. The United States, Japan and Western Europe and other countries have studied the application of 3D printing technology in the field of traditional casting since the $1990 \mathrm{~s}^{[6]}$. For example, Pratt \& Whitney Laboratory in 
the United States manufactured more than 2,000 castings in 1994 using 3D printing technology combined with traditional casting technology ${ }^{[7]}$. At the same time, HUST and Beijing Longyuan Co., Ltd. also began to apply SLS technology to rapid casting ${ }^{[8-9]}$. For instance, the team from HUST used the self-developed SLS system to prepare coated sand molds in $1998^{[10]}$. Compared with other additive manufacturing technologies, SLS technology possesses the advantages of abundant material selection, non-toxicity, and easy storage. In addition, the process is simple and does not require additional support structures, which is especially suitable for small batches of personalized customization parts with complex shapes and structures ${ }^{[4]}$.

In this study, the basic principle and characteristics of SLS powder technology were introduced, and the research status, key technologies and development trend of SLS in the fields of forming coated-sand mold casting and investment casting pattern were mainly described.

\section{Basic principle and characteristics of SLS}

The working principle of selective laser sintering is shown in Fig. 1. It has a wide range of forming materials, including coated sand, polymer, ceramics and other powder materials. Figure 2 shows coated sand core, wax based casting pattern and ceramic parts prepared by SLS technique ${ }^{[13]}$. At present, the major SLS forming equipment manufacturers, both domestic and abroad, include: 3D Systems, EOS, Beijing Longyuan AFS Co., Ltd., Huake 3D Technology Co., Ltd., Farsoon Technologies, etc ${ }^{[11]}$. Table 1 shows some equipment models and parameters.

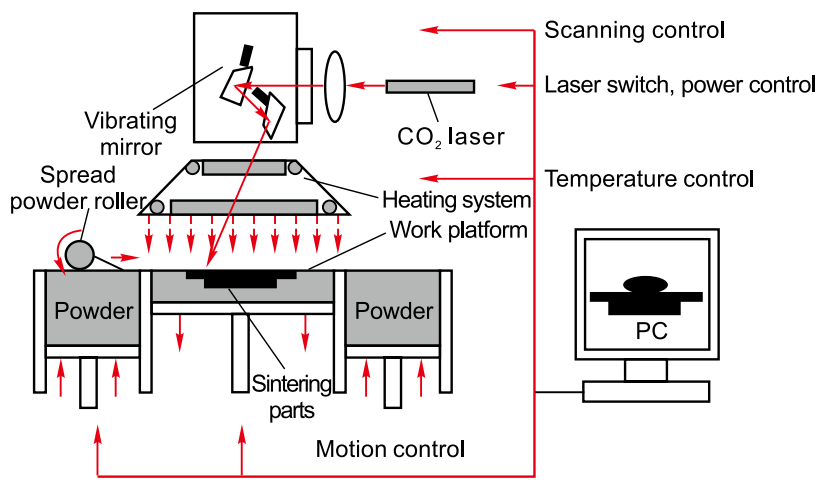

Fig. 1: Schematic diagram of selective laser sintering ${ }^{[12]}$
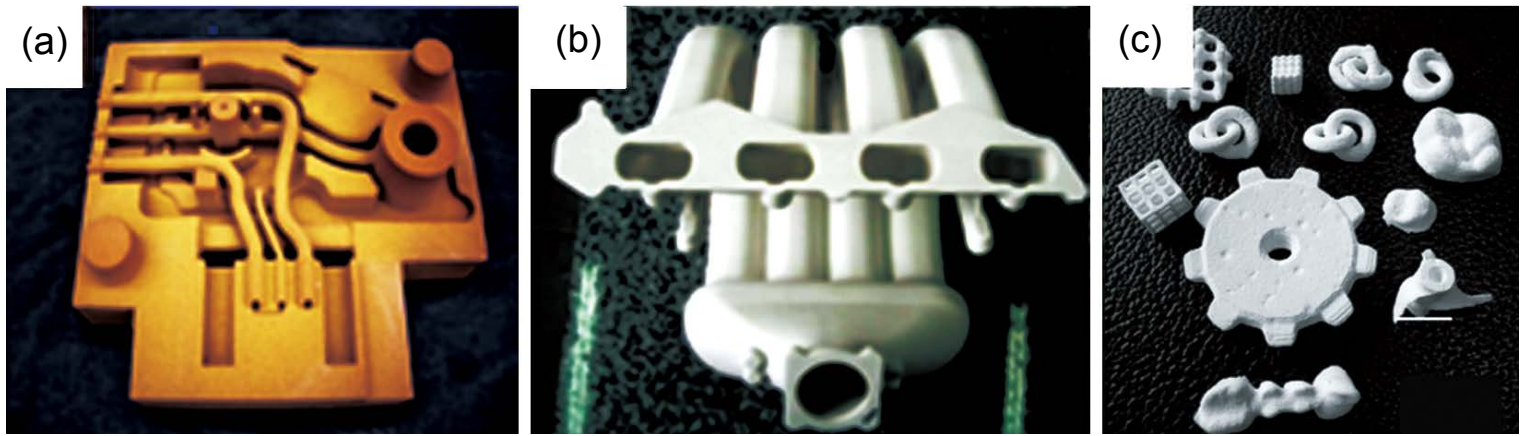

Fig. 2: Images of different items formed by SLS of various materials: (a) coated sand; (b) wax pattern; (c) ceramics ${ }^{[13]}$

Table 1: Manufacturers and parameters of SLS equipment at home and abroad ${ }^{[14-18]}$

\begin{tabular}{|c|c|c|c|c|c|}
\hline Manufacturer & $\begin{array}{l}\text { Build dimension } \\
\qquad\left(\mathrm{mm}^{3}\right)\end{array}$ & Laser type & Model & $\begin{array}{l}\text { Layer thickness } \\
(\mathrm{mm})\end{array}$ & $\begin{array}{l}\text { Scanning speed } \\
\left(m \cdot s^{-1}\right)\end{array}$ \\
\hline \multirow{2}{*}{ 3D Systems } & $550 \times 550 \times 750$ & $\mathrm{CO}_{2}, 70 \mathrm{~W}$ & $\mathrm{sPro}^{\mathrm{TM}} 230$ & $0.08-0.15$ & 10 \\
\hline & $381 \times 330 \times 460$ & $\mathrm{CO}_{2}, 70 \mathrm{~W}$ & ProX $^{\circledast}$ SLS 6100 & $0.08-0.15$ & 12.7 \\
\hline \multirow{2}{*}{ EOS } & $700 \times 380 \times 380$ & $\mathrm{CO}_{2}, 70 \mathrm{~W}$ & EOS P810 & 0.12 & 6 \\
\hline & $200 \times 250 \times 330$ & $\mathrm{CO}_{2}, 30 \mathrm{~W}$ & $\begin{array}{l}\text { FORMIGA P } 110 \\
\text { Velocis }\end{array}$ & $0.06-0.10-0.12$ & 5 \\
\hline \multirow{2}{*}{ Beijing Longyuan AFS } & $1,050 \times 1,050 \times 650$ & $\mathrm{CO}_{2}, 120 \mathrm{~W}$ & LaserCore-6000 & $0.08-0.35$ & 6 \\
\hline & $700 \times 700 \times 500$ & $\mathrm{CO}_{2}, 55 \mathrm{~W}$ or $120 \mathrm{~W}$ & LaserCore-5300 & $0.08-0.35$ & 6 \\
\hline \multirow{2}{*}{ Huake 3D Technology } & $1,400 \times 1,400 \times 500$ & $\mathrm{CO}_{2}, 100 \mathrm{~W}$ & HK S1400 & $0.08-0.3$ & 8 \\
\hline & $800 \times 800 \times 500$ & $\mathrm{CO}_{2}, 100 \mathrm{~W}$ & HK S800 & $0.08-0.3$ & 8 \\
\hline \multirow{2}{*}{ Farsoon Technologies } & $1,000 \times 500 \times 450$ & $\mathrm{CO}_{2}, 100 \mathrm{~W}$ & HT1001P & $0.06-0.3$ & 15.2 \\
\hline & $400 \times 400 \times 450$ & Fiber laser $300 \mathrm{~W}$ & Flight 403P & $0.06-0.3$ & 20 \\
\hline
\end{tabular}


The application of SLS in the field of casting focuses on sand casting, investment casting, etc., specifically including: (1) using SLS technology to prepare investment patterns (wax pattern, resin pattern, etc.), and then combining investment precision casting to obtain metal castings; (2) directly preparing the sand mold (core) for casting based on coated sand as sintered material, followed by metal casting to obtain metal castings.

Due to the higher melting temperature of ceramic material, the laser beam adopted in SLS equipment can hardly sinter ceramic particles together in a short period of time. Recent studies ${ }^{[13]}$ have focused on mixing ceramic powders with polymer adhesives to prepare ceramic parts based on the SLS method, followed by debinding and sintering to obtain complex ceramic shell (core); but a ceramic shell (core) formation based on the SLS method has been rarely reported.

\subsection{SLS in sand casting}

Sand-mold casting, as the widely adopted manufacturing method in the traditional casting process, has great dependence on sand molds to determine the metal casting quality. The traditional manufacturing process of a sand mold (core) is complex, and the production cycle is long, especially for the sand mold (core) used in the production of various large and complex castings, which is often composed of multiple sand molds (cores). It is widely recognized that the assembly positioning accuracy is low, the surface quality is poor, and the cutting allowance is large, which leads to a lot of waste of raw materials, greatly increases processing cost, and seriously reduces production efficiency. SLS, as an additive manufacturing method, could directly fabricate sand molds with complex structures by sintering the coated sand particles, which has attracted great attention from both academic and industry fields.

The experimental study of direct sintering with coated sand as sintering material began in Europe in 1996 (such as EOS company in Germany) ${ }^{[8]}$. At the same time, Professor Fan systematically studied the process parameters of making coated sand mold (core) by SLS, analyzed the mechanism and characteristics of heat hardening of coated sand under laser irradiation, and poured a variety of metal castings ${ }^{[9,19-22]}$.

It is an outstanding application of rapid prototyping technology in the foundry industry that coated sand is used as sintering material, and the SLS method is used to directly form the mold (core) for casting ${ }^{[9,23-24]}$. Compared with the traditional sand mold casting method, the complex and bulky casting production process can be completed on the SLS machine, saving a lot of tooling equipment (forming machine, core making machine, transportation equipment, etc.), breaking through the bottleneck of complex sand mold (core) manufacturing difficulty and long production cycles ${ }^{[25-26]}$. As shown in Fig. 3, the sand molds of a hydraulic multi way valve were prepared by SLS, and the casting was obtained after pouring. The SLS prepared sand mold exhibited integrated appearance, and after casting, the relevant hydraulic valve casting with desired structures and surface quality was obtained.

\subsection{SLS in investment casting}

Investment casting can produce metal parts with a high surface finish and complex shape, and the corresponding preparation processes mainly include preparation of wax pattern, assembly of wax pattern, preparation of multilayer ceramic shell, dewaxing, shell sintering, pouring, removal of ceramic shell and post-treatment ${ }^{[28-31]}$, which has a long production cycle and many technological links.
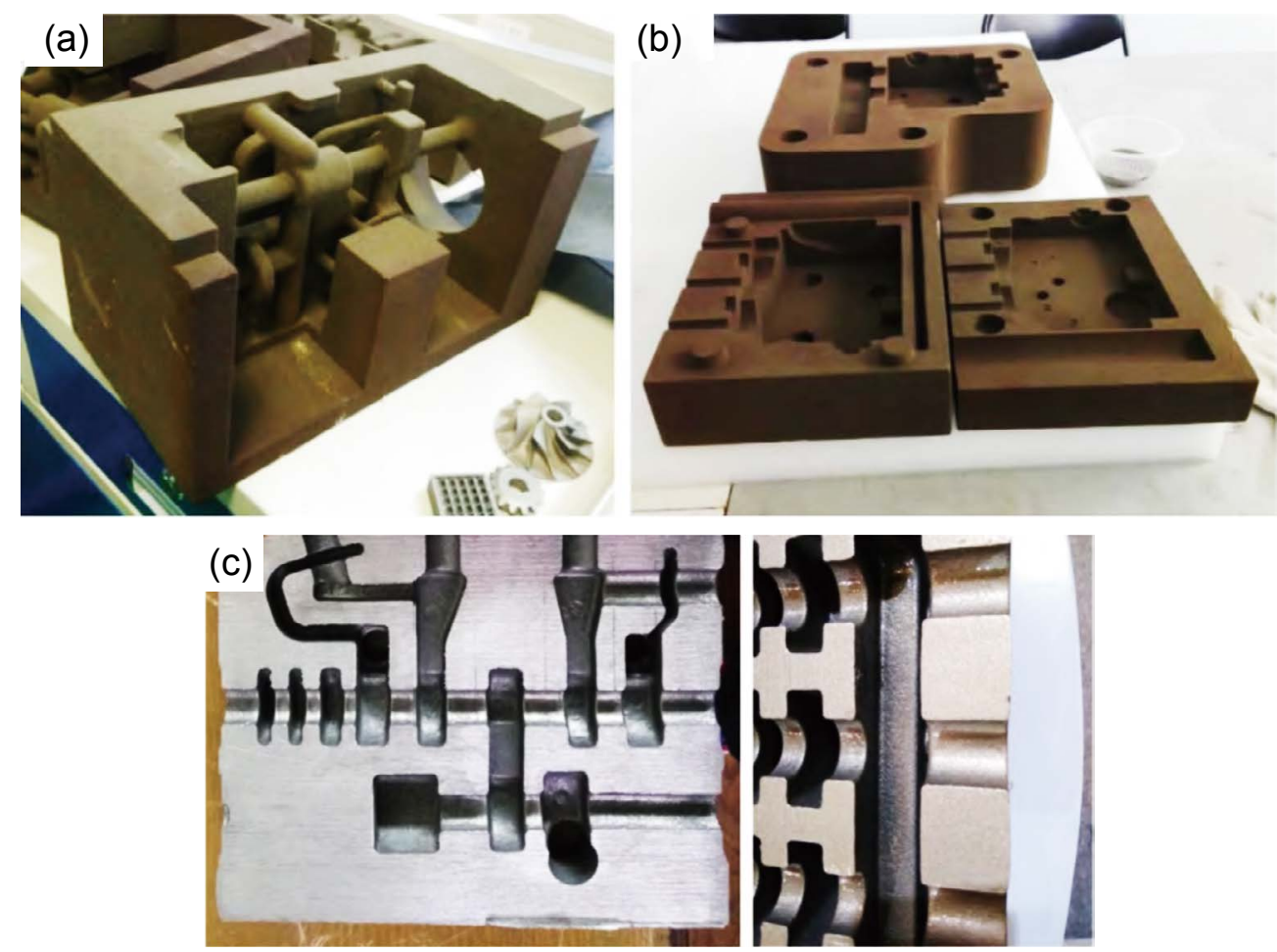

Fig. 3: SLS and sand casting: (a, b) sand mold of hydraulic multi way valve; (c) hydraulic valve casting blank ${ }^{[26]}$ 
Directly forming polymer-based patterns (wax pattern, resin pattern, etc.) through SLS method provides a novel solution for investment casting pattern preparation ${ }^{[32-33]}$. SLS technique has been adopted in investment casting since the 1990s. DTM company was the first, and then HUST, Nanjing University of Aeronautics and Astronautics, and Beijing Longyuan AFS Co., Ltd. in China, carried out relevant research ${ }^{[7,34-35]}$. A composite manufacturing procedure mixing SLS technique with investment casting can break through the limit of traditional pattern design, save the pattern development and manufacturing process, and shorten the production cycle. As shown in Fig. $4^{[12]}$, the casting polystyrene (PS) pattern is obtained by using SLS method and then followed by surface dipping wax, wax pattern assembly, shell making and pouring, after that, a rapid die-less manufacturing of a engine cylinder block is realized.
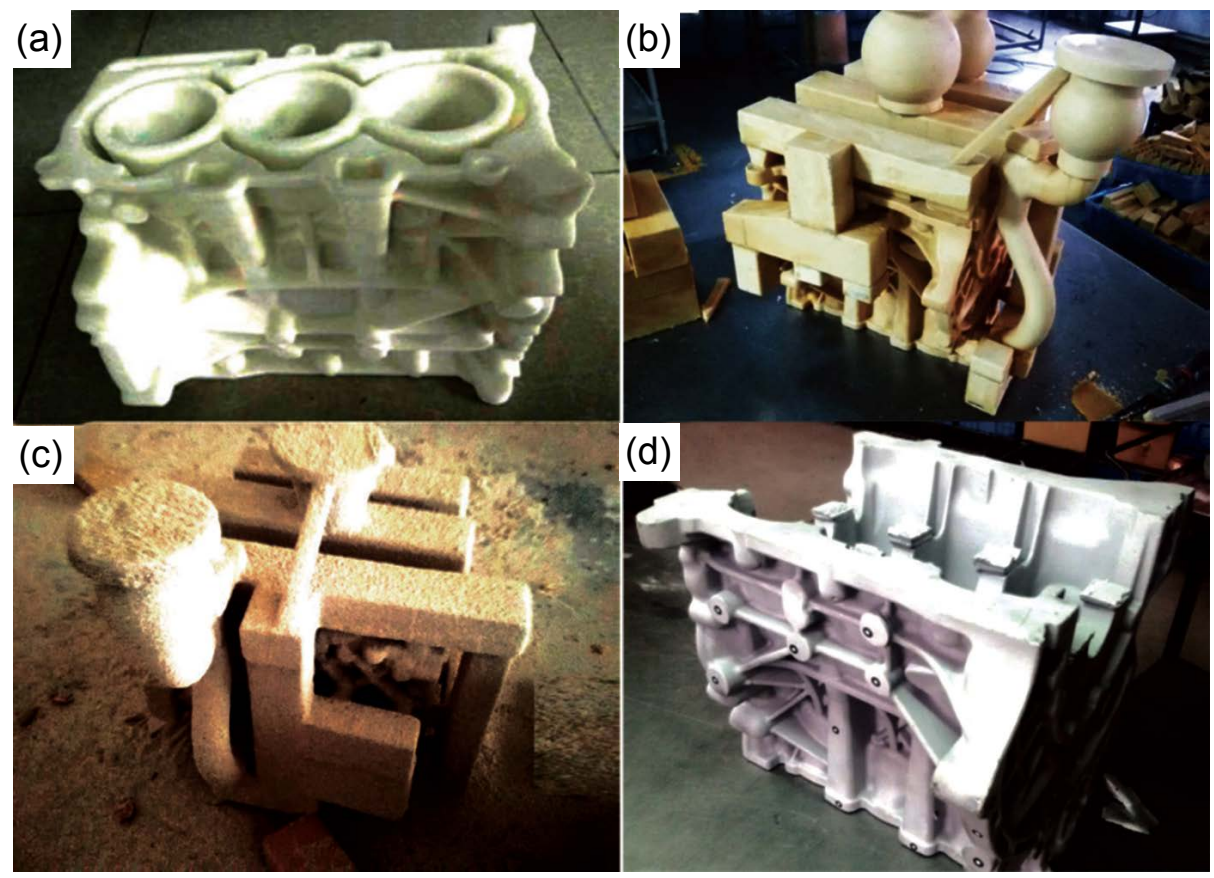

Fig. 4: SLS combined with investment precision casting: (a) wax pattern of SLS cylinder body; (b) wax pattern assembly; (c) shell making; (d) cylinder block casting ${ }^{[12]}$

\section{Key technologies in SLS}

SLS can rapidly prepare complex prototype parts and functional parts without additional support structure based on large variety of materials. It plays an important role in the field of additive manufacturing, and its main application in the casting field is the preparation of a coated sand mold and investment pattern, replacing the wax pattern in sand mold casting and investment casting.

\subsection{Materials adopted in SLS technique}

\subsubsection{Precoated sand materials}

According to the sintering and binding mechanism, coated sands adopted in SLS technology contain sand particles and binders that cover around the sand particles. The shape and size distribution of sand particles directly influence the formability, normally with a spherical shape and average diameter less than $0.20 \mathrm{~mm}$. Besides, binders used for coated sands are carefully formulated to combine the properties of rapidly binding the sand during laser processing and then improving strength during the drying processing. The coated sands adopted in SLS method are prepared using thermoplastic or thermosetting resin including phenolic resin coated quartz sand, zirconium sand or pearl sand ${ }^{[34]}$. Normally, the coated sands suitable for SLS method have good thermal conductivity, formability and thermoset, small diameter (less than $0.20 \mathrm{~mm}$ ), low gas evolution, and narrow softening temperature range. Furthermore, after laser sintering, the sand molds should have sufficient strength, and the waste residues should be easily removed.

\subsubsection{Materials for investment patterns}

Different from general patterns for investment casting, SLSbased pattern material as a polymer possesses high molecular weight, high melting temperature, no fixed melting point and a wide melting range. Due to the high viscosity of the molten polymers, high temperature is required to realize the dewaxing, thus, common water boiling or steaming cannot be adopted to dewax.

The main materials used to prepare the investment patterns are amorphous polymer materials, which possess an irregular and amorphous molecular chain, high melting viscosity, and correspondingly low sintering rate, resulting in low density, porous structure and poor strength of SLS formed parts. However, due to the small shrinkage deformation of amorphous polymer in the SLS forming process, the forming parts have high dimensional accuracy. Therefore, amorphous polymers are usually used to prepare products with low 
strength requirements but high dimensional accuracy, such as polycarbonate (PC), polystyrene (PS), high impact polystyrene (HIPS), etc., which are used in investment casting.

\subsection{SLS formation process}

The SLS equipment system is mainly composed of three parts: computer control system, host system and cooling system ${ }^{[9]}$.

(1) Computer control system is in charge of three-dimensional model processing, real-time control and simulation in the machining process.

(2) Host system consists of working cylinder, powder feeding cylinder, powder spreading system, galvanometer laser scanning system, temperature control system, fuselage and casing.

(3) Cooling system is adopted to cool the laser device, improve the stability of laser energy, protect the laser, extend its service life, and cool the galvanometer scanning system to ensure its stable operation.

In the SLS process, the powder under the laser irradiation generally goes through three stages: heating process, sintering process, and cooling process ${ }^{[36]}$, as shown in Fig. 5. For coated sand and polymer materials, different forming requirements and mechanisms are required. The forming process of two different materials is discussed briefly below.

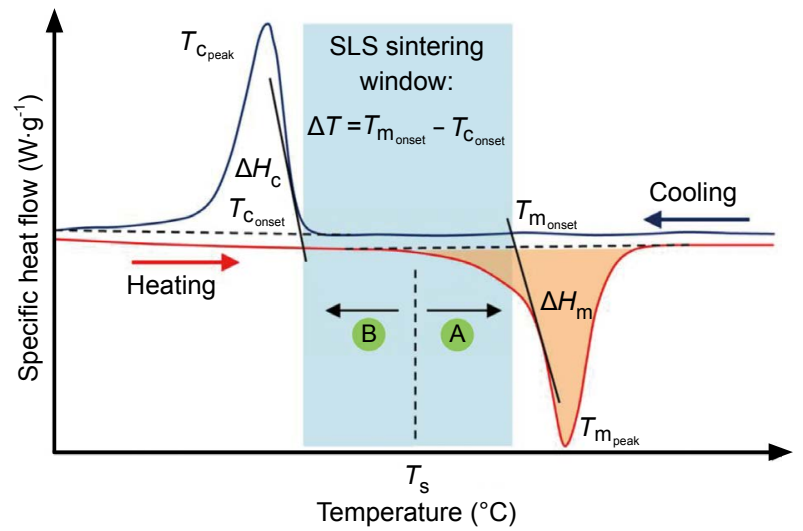

Fig. 5: Heating/cooling process of powders in SLS forming ${ }^{[36]}$ ( $T_{\mathrm{c}}$ : crystallization temperature, $T_{\mathrm{C}_{\text {onse }}}$ : starting temperature of crystallization, $T_{\mathrm{C}_{\text {peak }}}$ : maximum temperature of crystallization, $T_{\mathrm{m}}$ : melting temperature, $T_{\mathrm{m}_{\text {orset }}}:$ starting temperature of melting; $T_{\mathrm{m}_{\text {paak }}}:$ maximum temperature of melting, $\Delta H_{\mathrm{c}}$ : heat release of crystallization process, $\Delta H_{\mathrm{m}}$ : heat adsorption of melting process)

\subsubsection{SLS formed coated sand}

During laser sintering, the binder on the surface of sand particles melts, solidifies and hardens to form a connecting bridge as the medium among the sand particles to connect the dispersed sand particles ${ }^{[36-38]}$. Due to the difference between SLS formed coated sand mold/core and traditional sand mold/core, the following points should be considered in the process design of SLS mold/core: (1) the sintering area of the first layer should not be too small; (2) an inverted trapezoid structure should be avoided to prevent warpage; (3) a sintering island should be avoided in the sintering process; (4) a cantilever structure should be avoided ${ }^{[9]}$.
The heat curing of coated sand under laser irradiation is different from that of a shell mold (core) in casting production. When the surface of coated sand is scanned by laser beam, the conversion of light energy absorbed by the surface of coated sand to heat energy occurs instantaneously. At this moment, the heat energy is only limited to the laser irradiation area on the surface of coated sand. Through the subsequent heat conduction, the heat energy transfers from the high temperature region to the low temperature region. Therefore, a temperature gradient is formed between the surface and the inner layer, and the surface temperature of the coated sand contacted by the center of the laser beam is usually the highest. Although the instantaneous temperature of laser heating is very high, the duration is short, and thus, it is difficult to thoroughly melt and solidify the resin on the surface of coated sand, resulting in partial solidification ${ }^{[9,39]}$.

After scanning the sand surface with laser beam, the solidification degree of coated sand is related to the spot diameter $d_{0}$, scanning distance $P$, and thickness of sintered sand layer $\delta$. When the laser output power and scanning speed are constant, the corresponding thickness $h_{0}$ of the specific coated sand can solidify and the softening bond depth $h_{\mathrm{W}}$ can be regarded as constant. To generate connection among layers, the thickness of sintered sand layer $\delta$ should meet the requirement of $\delta<h_{\mathrm{W}}{ }^{[9,39]}$.

\subsubsection{SLS formed investment patterns}

The sintering mechanism of polymer powders in the SLS process is shown in Fig. $6^{[40]}$. During the sintering process, the powder at the center of the laser spot reaches the melting point first to form a melting pool rapidly. Then, with the continuous action of the laser energy, the unmelted powder in the zone of action begins to melt and flows to the molten pool. When the laser moves away rapidly, the molten pool solidifies with the decrease of temperature, and the whole part gradually cools down. The new layer is sintered by the laser and simultaneously bonded to the previous layer. This process repeats until the final 3D physical part is produced.

In the SLS forming process, the preheating temperature of amorphous polymer material should not exceed its glass

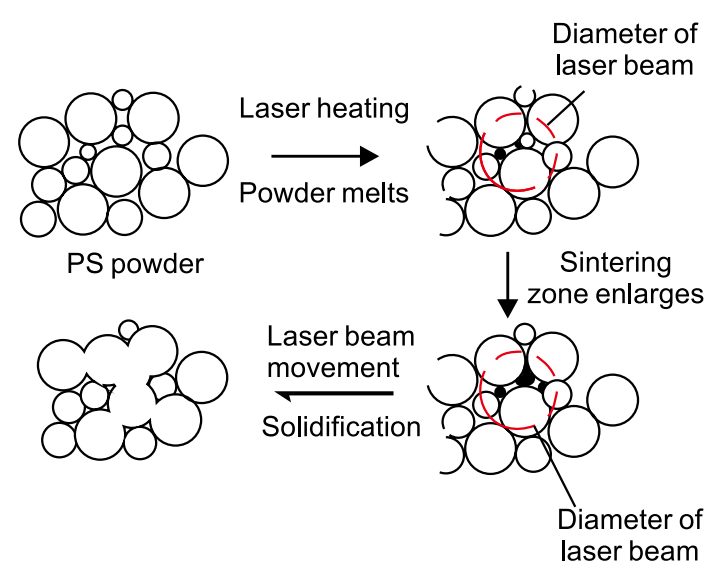

Fig. 6: Sintering mechanism of polymer powders of SLS process 
transition temperature $\left(T_{\mathrm{g}}\right)$ to reduce the warpage during sintering formation. Theoretically, increasing the laser energy density facilitates improving the density and strength of the sintered parts, but too high a laser energy density will reduce the strength of the sintered parts, deteriorate the dimensional accuracy and appear warpage ${ }^{[4]}$. Therefore, the main process parameters (laser power, spot size, scanning distance, scanning speed, single layer thickness, powder bed temperature, etc.) of SLS forming should be comprehensively considered to obtain the investment pattern with better performance and surface quality.

\subsubsection{SLS forming process simulation}

The forming process of SLS is extremely complex. During the forming process of coated sand and polymer molds (cores), the laser heat source melts the material through heat transfer, convection and radiation. The finite element method can be used to simulate the thermal effect of the sintering process and the flow process of the molten powder material. In recent years, the numerical simulation of the SLS has been a great concern to experts and scholars at home and abroad. The finite element model is established by finite element software to simulate the temperature field and stress field of the SLS and to optimize the process parameters.

Liu ${ }^{[41]}$ carried out the multi-field coupling simulation analysis of the coated sand sintering process to obtain the temperature field data and a multi-particle model for sintering neck. In addition, the variation law of processing parameters and binder ratio on the simulation results was discussed, and the results indicated that as the sintering time was $400 \mathrm{~ms}$, strong sintering necks among particles were generated, and as the binder content (thermoplastic phenolic resin) was $6 \%$, the size of sintering neck reached $35 \mu \mathrm{m}$. The simulation results provide theoretical support for the preparation of coated sand materials and optimization of sintering process parameters.

Yan et al. ${ }^{[4]}$ established a numerical simulation technology route for the composite process of cold isostatic pressing (CIP) and furnace sintering (FS) for selected laser sintering alumina ceramics. It lays the foundation for the SLS/CIP/FS composite process to form complex ceramic parts and improves the forming accuracy of the parts.

Meng et al. ${ }^{[42]}$ developed the finite element simulation software and investigated the effects of laser power, laser scanning rate and preheating temperature on the SLS peak temperature during the numerical examples. The peak temperature increases with the increase of laser power and preheating temperature, and decreases with the increase of laser scanning rate. The scanning path has negligible effect on the peak temperature of polymer powder during SLS process.

Peyre et al. ${ }^{[43]}$ carried out a dual experimental-numerical approach to estimate thermal cycles and sintering thickness obtained during SLS of PA12 and PEKK. The numerical calculations indicate that most of the incident laser light is either reflected or diffused in the powder bed.

In summary, recent simulation on the SLS process has focused on the temperature field concerning SLS process conditions and material parameters, but few works discuss the flow of melting model and bonding mechanism. Future research on finite element simulation on flow models of coated sands and polymer molecules during the SLS process should be carried out, which will greatly benefit enhancing the surface and dimension accuracy. Simulation combining the SLS process and specific casting process remains as another promising field in further research.

\subsection{Post-treatment for SLS}

Post-treatment (heating curing, surface finishing, dip coating, etc.) is necessary for SLS prepared samples to improve the surface quality and enhance the strength. There are different post-treatment methods corresponding to different SLS materials.

\subsubsection{Post-treatment for SLS formed coated sand}

The initial strength of coated sand hardened by laser beam scanning irradiation is relatively weak, and the corresponding explanations are: (1) the irradiating time of laser beam is very short; (2) the thermal conductivity of coated sand is low; (3) the maximum heating temperature of beam irradiation is not allowed to be too high (when the maximum temperature is higher than $300{ }^{\circ} \mathrm{C}$, the resin film is heated and carbonized). The thickness of the sintering layer, the thermal conductivity of the material, and the irradiation temperature of the laser beam (mainly depending on the output power and scanning speed of the laser beam) have great influence on the sintering strength. Besides, the coated sand mold (core) formed by SLS must be cured to meet the requirements of metal casting.

In addition, the surface of the sand mold is rough due to the step effect during formation. For the SLS mold (core) with split sintering, the inner wall of the mold cavity can be polished after heat preservation treatment to reduce the surface roughness of the mold cavity; for the SLS mold (core) with integral sintering, a coating procedure is necessary to improve surface quality. After coating, the mold (core) should be dried twice to remove the moisture and volatile matter in the coating.

\subsubsection{Post-treatment for SLS formed investment pattern}

Due to the high porosity, low strength and rough surface of the investment pattern parts formed by SLS, it is necessary to carry out post-treatment. At present, the widely adopted method is wax or resin infiltration, which could enhance surface accuracy and strength concurrently, and also benefit subsequent polishing. In addition, in order to meet the requirements of investment casting, the SLS pattern must be completely removable or burnt out during dewaxing.

\section{Practical applications of SLS in rapid casting}

As previously mentioned, the applications of SLS method in rapid casting mainly include sand-mold casting and investment casting. In this section, several practical applications are introduced in detail. 


\subsection{SLS application in sand-mold casting}

The application of SLS-based rapid casting has focused on mold forming. Currently, the poor formability of coated sand mold (core) remains as an important problem at this stage, and current research on SLS molding coated sand focuses on the material selection, optimization of process parameters, and improvement of mold (core) strength and accuracy.

Wen et al. ${ }^{[4]}$ prepared a large sand mold for a complex six- cylinder diesel engine cylinder head by SLS technology based on new adhesive coated alumina sand, and finally obtained castings with surface quality and dimensional accuracy to meet the design requirements. The sand mold and castings are shown in Fig. $7^{[44]}$. The materials and method proposed not only shortened the trial production cycle of the six-cylinder engine from five months for the traditional casting method to 10 days, but also reduced the cost and improved the casting quality.
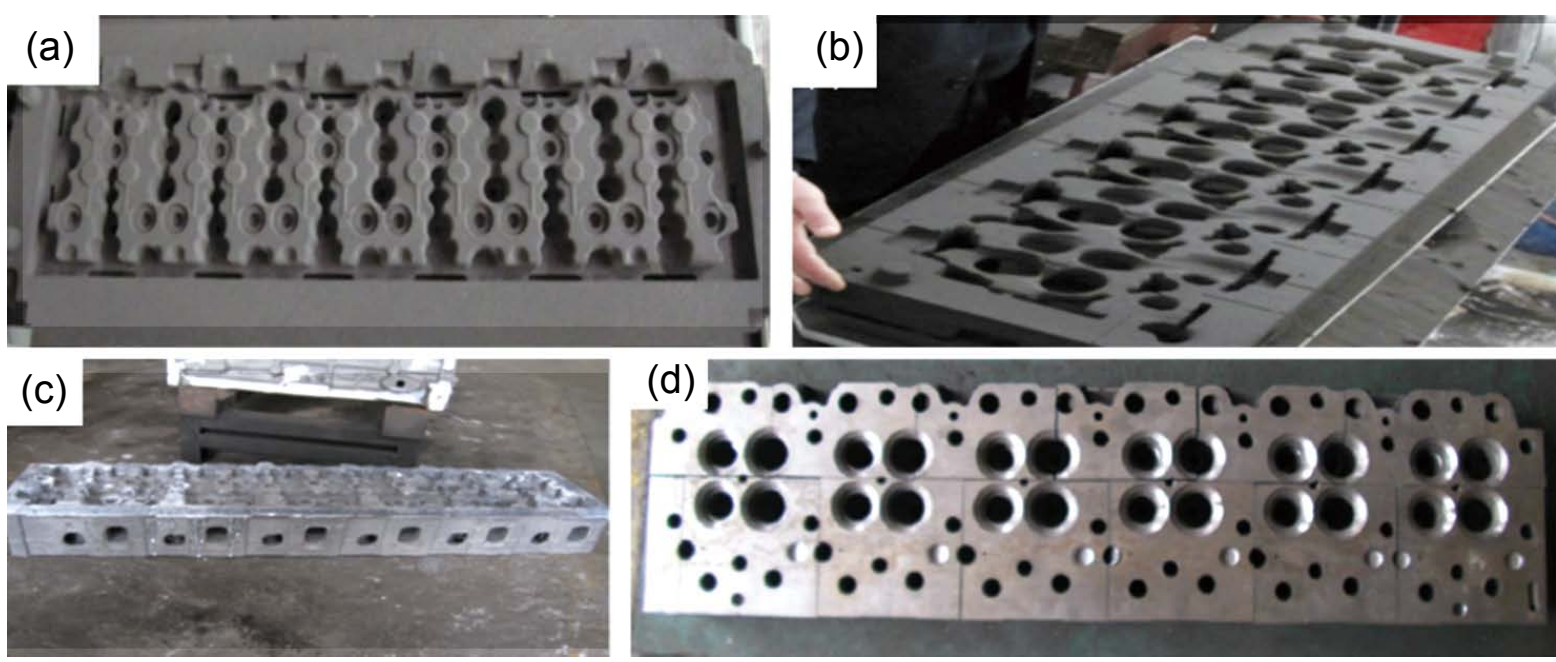

Fig. 7: SLS-based sand mold and casting: $(a, b)$ sand mold; $(c, d)$ casting of cylinder head of six-cylinder diesel engine ${ }^{[44]}$

Liang et al. ${ }^{[45]}$ prepared coated zircon sand by thermal or cold coating method, and studied the influence of the single scanning area, and the laser power of SLS on tensile strength of the coated zircon sand molds. The results showed that with the same resin content, the tensile strength of the SLS formed by the thermal coating method was higher than that of the cold coating method. As the single scanning area increased, the corresponding tensile strength of the coated zircon sand mold was decreased. Besides, as laser power increased, the corresponding tensile strength was enhanced, but as the laser power exceeded $45 \mathrm{~W}$, the sand mold surface quality was decreased due to sand clogging. As the binder content of $115 / 170$ mesh coated zircon sand was $2 \%$, the scan area was about $1900 \mathrm{~mm}^{2}$, appropriate laser power was $35 \mathrm{~W}$, the zircon coated sand molds were successfully prepared, and the titanium castings with clear outline and bright surface were cast.

$\mathrm{Xu}$ et al. ${ }^{[46]}$ studied the influence of laser energy density on the precision and tensile strength of SLS resin coated sand. The coated sand was coated with $1.5 \mathrm{wt} . \%$ resin with a particle size of 75-150 $\mu \mathrm{m}$. The experimental results showed that as the energy density range of laser sintering was $0.024-$ $0.032 \mathrm{~J} \cdot \mathrm{mm}^{-2}$, the tensile strength and dimensional accuracy of the sample were the best, and the composite coated sand mold with clear shape and high molding accuracy was successfully prepared, as shown in Fig. 8.

Cheng et al. ${ }^{[47]}$ studied the optimization design of SLS process parameters of a precoated sand mold. The effects of laser power, scanning speed, layer thickness, scanning distance, and their interactions on the dimensional accuracy

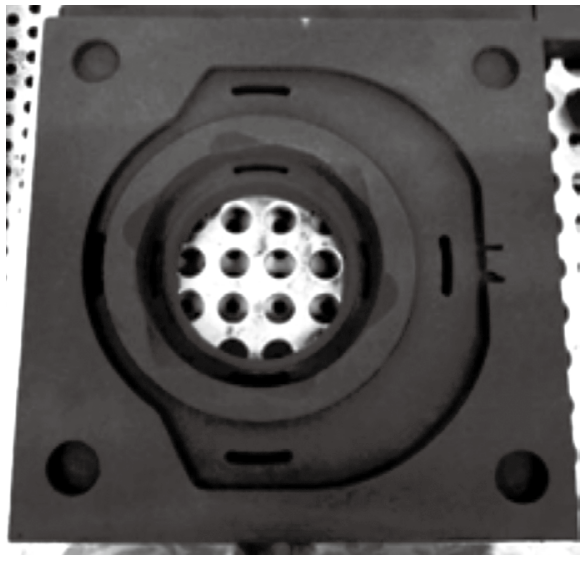

Fig. 8: Composite coated sand mold prepared by SLS ${ }^{[46]}$

of coated sand mold SLS were studied. The results showed that the dimension error along the length and width of the die was dominant. By using Taguchi's parameter design, the best parameter setting was settled to minimize the size error. The optimum parameters were obtained: laser power $11 \mathrm{~W}$, scanning speed $1,200 \mathrm{~mm} \cdot \mathrm{s}^{-1}$, layer thickness $0.5 \mathrm{~mm}$, and scanning spacing $0.25 \mathrm{~mm}$. The dimensional accuracy of the combination of these parameters could be increased by about $25 \%$ on average.

Although the sand particles and binder system adopted in the SLS technique are similar to those adopted in conventional sand molding method, after optimizing processing parameters, the sand molds or cores prepared through the SLS method show comparative properties compared to conventional methods, as shown in Table 2. 
Table 2: Comparisons of materials and properties of SLS method and conventional method

\begin{tabular}{|c|c|c|c|c|c|}
\hline Methods & Sand particle & Binder system & Processing conditions & Properties & Reference \\
\hline \multirow{3}{*}{ SLS technique } & $\begin{array}{c}100-210 \mu \mathrm{m} \mathrm{Al}_{2} \mathrm{O}_{3} \\
\text { sand particles: regular } \\
\text { spherical shape }\end{array}$ & $\begin{array}{c}\text { Mixture of phenolic } \\
\text { resin and } \\
\text { hexamethylenetetramine }\end{array}$ & $\begin{array}{l}\text { Laser power: } 50 \mathrm{~W} \text {; } \\
\text { layer thickness: } \\
0.25-0.30 \mathrm{~mm} ; \\
\text { Scanning speed: } 4 \mathrm{~m} \cdot \mathrm{s}^{-1}\end{array}$ & $\begin{array}{l}\text { Tensile strength: } \\
6.85 \pm 0.46 \mathrm{MPa} \text {; } \\
\text { Gas content at } 1,000^{\circ} \mathrm{C} \text { : } \\
21.83 \pm 0.58 \mathrm{~mL} \cdot \mathrm{g}^{-1}\end{array}$ & [44] \\
\hline & $\begin{array}{l}\text { Zircon sand: } \\
90-125 \mu \mathrm{m}\end{array}$ & $\begin{array}{l}\text { Thermoplastic phenolic } \\
\text { resin }\end{array}$ & $\begin{array}{l}\text { Laser power: } 35 \mathrm{~W} \text {; } \\
\text { Scanning area: } \\
3 \times 19 \mathrm{~cm}^{2}\end{array}$ & $\begin{array}{c}\text { Tensile strength: } \\
\text { 3.2 MPa } \\
\text { Gas content: } 30 \mathrm{~mL} \cdot \mathrm{g}^{-1}\end{array}$ & [45] \\
\hline & $\begin{array}{c}\text { Spherical Baozhu } \\
\text { sand: } 75 \text { to } 150 \mu \mathrm{m} \text {, } \\
\text { angular coefficient } \\
<1.1\end{array}$ & $\begin{array}{l}\text { Thermoplastic phenolic } \\
\text { resin, methenamine } \\
\text { curing agent and KH550 } \\
\text { coupling agent }\end{array}$ & $\begin{array}{l}\text { Laser power: } 30-40 \mathrm{~W} \\
\text { Scanning speed: } \\
1.5-2.0 \mathrm{~m} \cdot \mathrm{s}^{-1}\end{array}$ & $\begin{array}{c}\text { Tensile strength: } \\
0.34 \mathrm{MPa} \\
\text { Dimensional accuracy: } \\
\pm 0.25 \%\end{array}$ & {$[46]$} \\
\hline $\begin{array}{l}\text { Conventional sand } \\
\text { molding }\end{array}$ & $\begin{array}{l}\text { Spherical sands: } \\
100-270 \mu \mathrm{m}\end{array}$ & Phenolic resin & $\begin{array}{l}\text { Curing temperature: } \\
\qquad 85^{\circ} \mathrm{C} ; \\
\text { Holding time: } 120 \text { min }\end{array}$ & $\begin{array}{l}\text { Tensile strength: } \\
1.35 \mathrm{MPa} ; \\
\text { Gas content: } \\
7.83 \mathrm{~mL} \cdot \mathrm{g}^{-1}\end{array}$ & [48] \\
\hline
\end{tabular}

\subsection{SLS application in investment casting}

Another important application of SLS technology in the casting field is to prepare the investment pattern. Polycarbonate was firstly developed for SLS forming polymer patterns because of its excellent laser sintering performance and high strength. However, the melting point of polycarbonate is relatively high, and the fluidity is not good, so it needs a higher calcination temperature. Nowadays, polystyrene and high impact polystyrene are widely used as raw materials in SLS technology to prepare an "investment pattern".

Sun et al. ${ }^{[49]}$ prepared polystyrene-wax composite patterns based on SLS technique, and treated patterns with conventional investment casting procedures. The obtained blade casting possessed a dimension accuracy of -0.02-0.65 mm, and surface roughness Ra was 2.86-6.19 $\mu \mathrm{m}$, which required post-treatment to further enhance dimension accuracy and surface quality.

Gökhan et al. ${ }^{[50]}$ prepared polystyrene patterns based on the SLS technique, and coated patterns with gypsum slurry to enhance surface quality. After drying, dewaxing and sintering, a gypsum-based ceramic shell was obtained. It was found that the surface roughness of as-built patterns was high $(\mathrm{Ra}>10 \mu \mathrm{m})$, but after a wax covering, the surface roughness could be greatly reduced to $3.2 \mu \mathrm{m}$.

Further, Wang et al. ${ }^{[51]}$ prepared polystyrene patterns [as shown in Fig. 9(a)] based on the SLS technique, and coated with silica sol-zirconite composite slurry. After drying in ambient environment for $24 \mathrm{~h}$, dewaxing and sintering, a ceramic shell with thickness of $5.5 \mathrm{~mm}$ was obtained. A stainless steel blade with desired shape retention and surface quality was obtained after investment casting, as shown in Fig. 9(b). Compared with traditional investment casting procedures, the introduction of SLS method facilitates shortening processing cost and period, as well as improving casting quality.
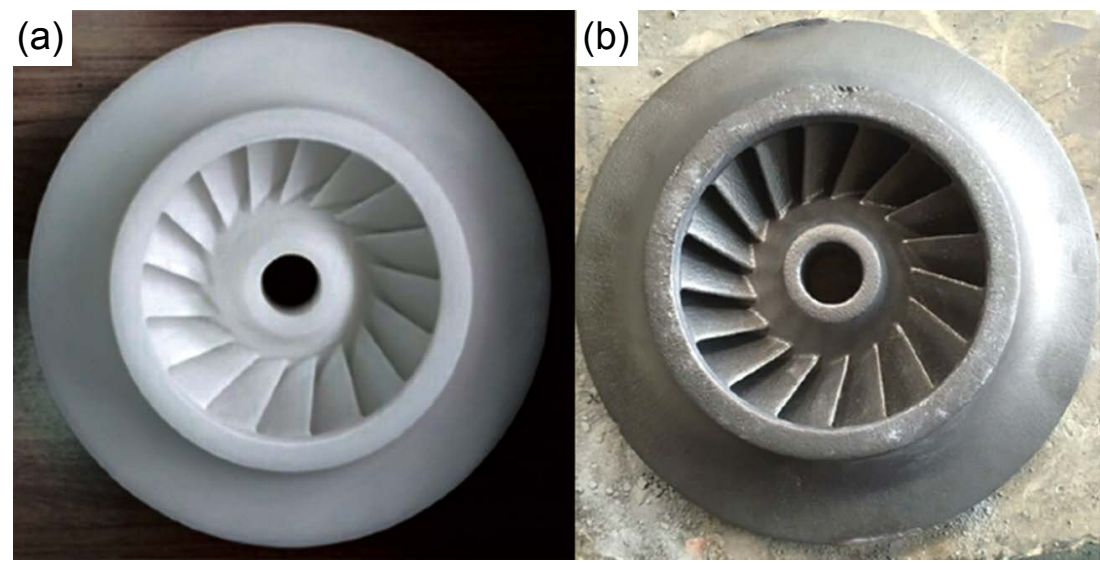

Fig. 9: SLS-based forming "wax pattern" and casting: (a) SLS polymer pattern; (b) stainless steel impeller casting ${ }^{\text {[11] }}$ 
To enhance mechanical properties and surface quality, Shi et al. ${ }^{[52-54]}$ applied post-processing methods including immersing epoxy resin and wax to SLS formed polystyrene and high impact polystyrene structures. After infiltrating wax, the tensile strength was increased by $64 \%$ to $7.54 \mathrm{MPa}$. As shown in Fig. 10, integral high impact polystyrene patterns suitable for investment casting were successfully prepared through the SLS technique, and corresponding metal castings were obtained after investment casting as shown in Fig. 11. The accuracy of the actual metallic parts can be controlled within $\pm 0.2 \mathrm{~mm}$.

Yang et al. ${ }^{[5]}$ carried out the research on the rapid investment casting process of complex surface parts based on the SLS technique (as shown in Fig. 12). SLS forming polystyrene was used to prepare the impeller resin pattern and after wax impregnation treatment, the shell of the inducer was prepared by dip-coating in silica sol. The results showed that the relative error range of dimension before wax immersion was $-0.185 \%-3.22 \%$, the single dimension of the model increased by $0.2-0.3 \mathrm{~mm}$ after wax immersion, and the average surface roughness was $0.647 \mu \mathrm{m}$. The inducer with good internal and external quality was obtained under preheating temperature of $1,115{ }^{\circ} \mathrm{C}$ and pouring temperature of $1,600{ }^{\circ} \mathrm{C}$. The average dimension error was $0.17 \%-0.19 \%$, and the average surface roughness was $0.693 \mu \mathrm{m}$, which indicated that wax immersion facilitated improving dimension accuracy and surface quality.
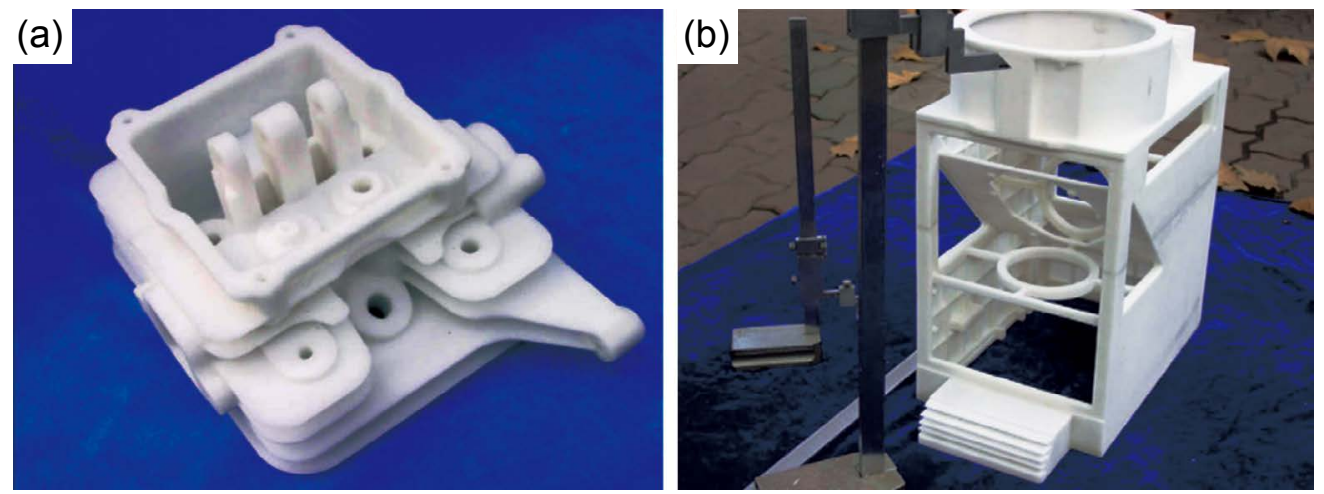

Fig. 10: High impact polystyrene sample formed by SLS for investment casting: (a) delicate structure; (b) thin-walled structure ${ }^{[54]}$
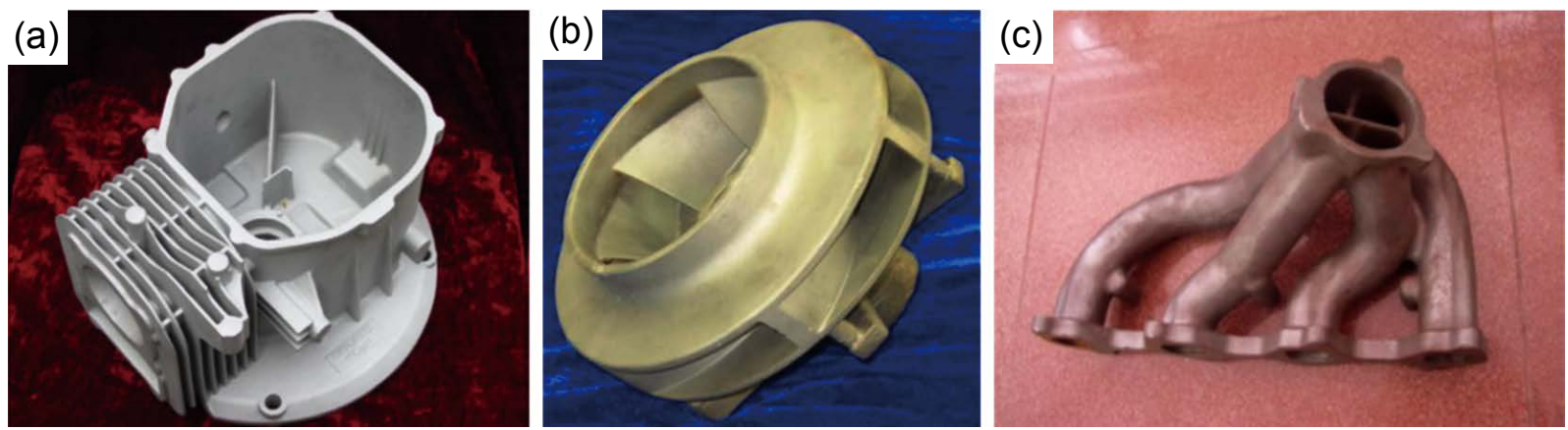

Fig. 11: Casting prepared by SLS combined with investment casting: (a) cylinder block of motorcycle engine; (b) stainless steel pump wheel; (c) vehicle exhaust pipes ${ }^{[54]}$
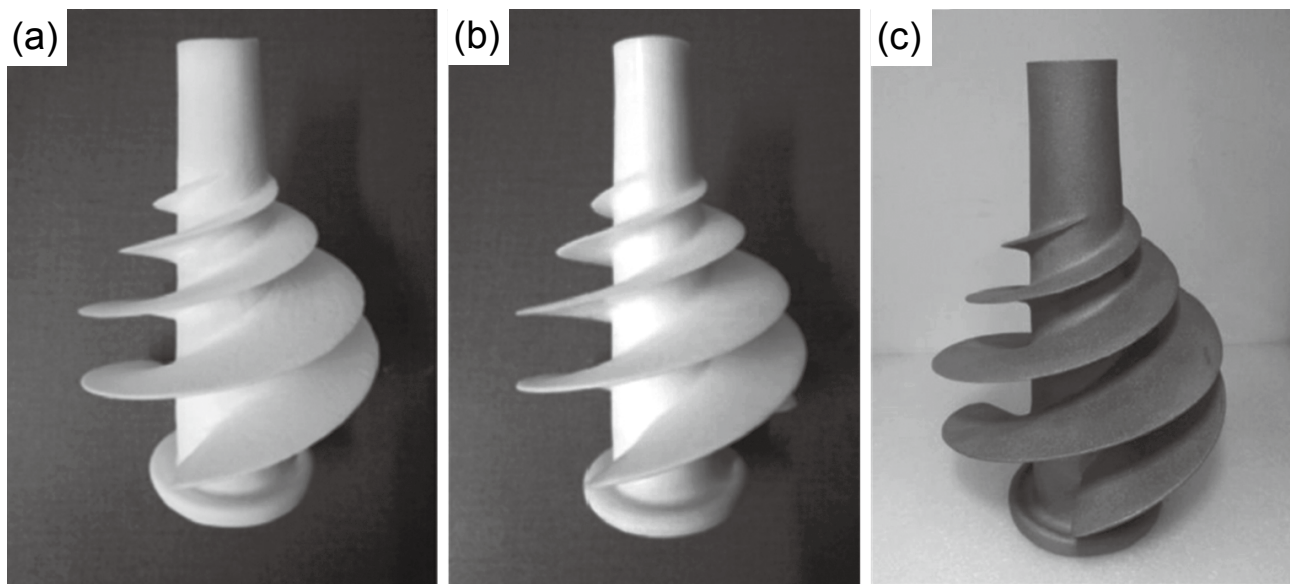

Fig. 12: Polystyrene pattern and casting prepared by SLS: (a) polystyrene pattern; (b) paraffin treatment; (c) casting of inducer wheel ${ }^{[55]}$ 
In summary, the coated sand mold and investment patterns prepared by SLS can be used to prepare different metal castings, such as cast steel, cast iron, titanium alloy, magnesium alloy, aluminum alloy, stainless steel, and so on Table 3 shows printing materials, metal types, casting quality, etc.

Table 3: Type and accuracy of castings prepared by SLS

\begin{tabular}{|c|c|c|c|}
\hline Forming materials & Metal types & Precision & References \\
\hline $\begin{array}{c}\text { Coated sand (zirconium sand, } \\
\text { ceramic sand, etc.) }\end{array}$ & $\begin{array}{l}\text { Steel, iron, magnesium } \\
\text { alloy, titanium alloy, etc. }\end{array}$ & $\begin{array}{c}\text { The dimensional accuracy is } \\
\text { generally CT6-8, and the surface } \\
\text { roughness is generally } \\
12.5-3.2 \mu \mathrm{m}\end{array}$ & {$[4],[44],[45],[56]$} \\
\hline $\begin{array}{l}\text { Polystyrene, high impact } \\
\text { polystyrene }\end{array}$ & $\begin{array}{c}\text { Stainless steel, aluminum } \\
\text { alloy, etc. }\end{array}$ & $\begin{array}{l}\text { The dimensional accuracy is } \\
\text { generally CT6, and the surface } \\
\text { roughness }(\mathrm{Ra}) \text { is generally } \\
\text { less than } 6.3 \mu \mathrm{m}\end{array}$ & [49], [50], [54] \\
\hline
\end{tabular}

\section{Summary}

In this study, the application of selective laser sintering (SLS) in the field of casting was reviewed. Rapid casting based on SLS technique was suitable for materials including coated sands and polymer particles, and correspondingly, sand casting and investment casting based on SLS technique has attracted researchers' attention. By conducting material regulation, parameter optimization and post treatment, SLS based rapid casting could prepare castings with comparable surface and performance to conventional methods. However, there remains a long way to achieve industrial production. In future, research development should be enhanced in the following aspects to make SLS more practical in the metal casting field:

(1) The price of SLS equipment is high, so it is of great significance to further improve the processing efficiency and reduce the cost of industrial grade SLS equipment, so as to promote and expand the application of SLS in the casting field.

(2) Develop new SLS powder materials and post-treatment process for direct and low-cost molding of polymers, ceramics and even metal components.

(3) A new dip coating for SLS mold (core) is required to improve the surface precision of the mold (core) and the surface finish of the casting.

\section{Acknowledgements}

This work was supported by the National Key R\&D Program of China (2020YFB2008300, 2020YFB2008304), and the National Natural Science Foundation of China (51775204, 51375190, 59635040).

\section{References}

[1] Sing S L, Yeong W Y, Wiria F E, et al. Direct selective laser sintering and melting of ceramics: A review. Rapid Prototyping Journal, 2017, 23(3): 611-623.

[2] Deckard C R. Method and apparatus for producing parts by selective sintering. Patent: United States, 4863538, 1989.

[3] Pan Y F, Shen Y F, Gu D D, et al. Present status of development for selective laser sintering (SLS). Tool Engineering, 2004, 6: 3-7. (In Chinese)
[4] Yan C Z, Shi Y S, Wei Q S, et al. Laser selective sintering 3D printing technology. Wuhan: Huazhong University of Science and Technology Press, 2019. (In Chinese)

[5] Ren J W, Peng B. Reviews and prospects for selective laser sintering (SLS). Machinery Design \& Manufacture, 2009, 10: 266-268. (In Chinese)

[6] Duan W C, Gao J J, Dong B B, et al. Status and prospect of the $3 \mathrm{D}$ printing technique in the field of metal casting. Foundry Technology, 2018, 39(12): 2895-2900. (In Chinese)

[7] Huang S H, Zhang $X \mathrm{~L}$, Ma L, et al. State-of-the-art in worldwide rapid prototyping manufacturing. China Mechanical Engineering, 1997, 8(5): 8-12. (In Chinese)

[8] Fan Z T, Huang N Y, Luo J R, et al. Evaluation of the methods to produce metal parts by RPM. China Mechanical Engineering, 1997, (5): 25-26. (In Chinese)

[9] Fan Z T. Basic research on materials and technology in rapid prototyping of metal parts. Doctoral Dissertation, Wuhan: Huazhong University of Technology, 1999. (In Chinese)

[10] Fan Z T, Huang N Y, Li Y, et al. Investigating on casting mold making with coated sand by the selected laser sintering. In: Progress in Rapid Prototyping Manufacturing and Rapid Tooling, Beijing, 1998, 412-418.

[11] Gong $Y X$, Wang Q S, Zhu L J, et al. Review on the progress of forming equipment and materials for SLS. Foundry, 2017, 66(3): 258-262. (In Chinese)

[12] Song B, Cai $Y \mathrm{~S}, \mathrm{Xu} \mathrm{H}$, et al. Application of 3D printing technology in rapid investment casting of bimetal engine block. Metal Working (Hot Processing), 2017, (7): 56-59. (In Chinese)

[13] Chen Z W, Li Z Y, Li J J, et al. 3D printing of ceramics: A review. Journal of European Ceramic Society, 2019, 39(4): 661-687.

[14] 3D Systems. Select Laser Sintering Printers. http://www.3dsystemschina.com/printers/\#p95, May 2020.

[15] EOS. EOS Polymer Systems. https://www.eos-apac.info/info2. php?class_id=110101101102\&id=465, May 2020.

[16] Longyuan AFS. Selective Laser Sintering Rapid Molding Machine-Product Center. http://www.lyafs.com.cn/products. aspx?id=4, August 2020.

[17] Huake 3D Technology. Product Center. http://www.huake3d. com/product_detail.asp?Product_ID $=45 \&$ Product_ParentID $=6$, July 2020.

[18] Farsoon Technologies. Farsoon Total Solutions for Polymer Additive Manufacturing. http://en.farsoon.com/solution_list_01. html, July 2020.

[19] Fan $Z T$, Huang $N$ Y, Yi Y, et al. Investigating on casting mold (or core) making with coated sand by the selected laser sintering. China Foundry, 2004, 1(2): 122-126. 
[20] Fan Z T, Huang N Y, Xiao Y J. Accuracy analysis of the part made by selected laser sintering. China Foundry, 2004, 1(1): 49-52.

[21] Fan $Z T$, Huang $N Y$, Song $X$ J, et al. The measures of improving the sintered strength of the coated sand mold (or core) made by selected laser sintering (SLS). Special Casting \& Nonferrous Alloys, 1999, 19(2): 1-4. (In Chinese)

[22] Fan Z T, Huang N Y, Chen Z M. Quick casting by selective laser sintering (SLS). Special Casting \& Nonferrous Alloy, 1999, 19(5): 7-9. (In Chinese)

[23] Li B, Liao H M, Zeng M, et al. Application and development of 3D printing in sand mold casting. Special Casting \& Nonferrous Alloy, 2020, 40(9): 953-957. (In Chinese)

[24] Li X. Basic research on materials and technology in rapid prototyping of metal parts. Doctoral Dissertation, Wuhan: Huazhong University of Technology, 2001. (In Chinese)

[25] Le Néel T A, Mognol P, Hascoët J. A review on additive manufacturing of sand molds by binder jetting and selective laser sintering. Rapid Prototyping Journal, 2018, 24(8): 1325-1336.

[26] Song J L, Li Y T, Deng Q L, et al. Rapid prototyping manufacturing of silica sand molds based on selective laser sintering. Journal of Materials Processing Technology, 2007, 187-188: 614-618.

[27] Bo F X, He B, Zong X M. Selective laser sintering process of coated sands. Laser \& Optoelectronics Progress, 2017, 54(9): 241-247. (In Chinese)

[28] Kanyo J E, Schafföner S, Uwanyuze R S, et al. An overview of ceramic molds for investment casting of nickel superalloys. Journal of the European Ceramic Society, 2020, 40(15): 49554973.

[29] Bao Y, Chen C, Zhu J, et al. Investment casting technology. Hangzhou: Zhejiang University Press, 2012. (In Chinese)

[30] Zhao X Z. Preparation and application of ceramic core. Beijing: Science Press, 2013. (In Chinese)

[31] Pattnaik S, Karunakar D B, Jha P K. Developments in investment casting process-A review. Journal of Materials Processing Technology, 2012, 212(11): 2332-2348.

[32] Feng D, Wang B, Qi F W, et al Research progress in the preparation of polymer-based materials for selective laser sintering. Chemical Industry and Engineering Progress, 2021, 40(8): 4280-4304. (In Chinese)

[33] Shi Y S, Yan C Z, Wei Q S, et al. Polymer based composites for selective laser sintering 3D printing technology. Science in China (Information Sciences), 2015, 45(2): 204-211. (In Chinese)

[34] Feng T, Sun J M, Zong G S. Rapid casting by selective laser sintering. China Mechanical Engineering, 1997, 8(5):116-117. (In Chinese)

[35] Tang $Y X$, Deng Q L, Zhang H, et al. Selective laser sintering and its application in precision casting of aviation parts. Aviation Precision Manufacturing Technology, 1996, 32(2): 21-24. (In Chinese)

[36] Amado Becker A F. Characterization and prediction of SLS processability of polymer powders with respect to powder flow and part warpage. Doctoral Dissertation, Zürich: ETH-Zürich, 2016.

[37] Casalino G, De Filippis LA C, Ludovico A D, et al. An investigation of rapid prototyping of sand casting molds by selective laser sintering. Journal of Laser Applications, 2002, 14(2): 100-106.

[38] Casalino G, De Filippis L A C, Ludovico A. A technical note on the mechanical and physical characterization of selective laser sintered sand for rapid casting. Journal of Materials Processing Technology, 2005, 166(1): 1-8.

[39] Fan Z T, Huang N Y. Mechanism of coated sand mold (core) hardened by selective laser sintering. Journal of Huazhong University of Science and Technology, 2001, 29(4): 60-62. (In Chinese)
[40] Zeng Z, Deng X H, Cui J M, et al. Improvement on selective laser sintering and post-processing of polystyrene. Polymers, 2019, $11(6): 956$.

[41] Liu T L. Numerical simulation and experimental study on selective laser sintering of Baozhu coated sand. Masteral Dissertation, Harbin: Northeast Forestry University, 2019. (In Chinese)

[42] Meng J, Ding H L, Yan B. Three dimensional simulation of peak temperature of selective laser sintering by finite element method. Polymer Materials Science and Engineering, 2020, 36(1): 83-88. (In Chinese)

[43] Peyre P, Rouchausse Y, Defauchy D, et al. Experimental and numerical analysis of the selective laser sintering (SLS) of PA12 and PEKK semi-crystalline polymers. Journal of Materials Processing Technology, 2015, 225: 326-336.

[44] Wen S F, Shen Q W, Wei Q S, et al. Material optimization and post-processing of sand moulds manufactured by the selective laser sintering of binder-coated $\mathrm{Al}_{2} \mathrm{O}_{3}$ sands. Journal of Materials Processing Technology, 2015, 225: 93-102.

[45] Liang X W, Wang D Q, Xu Z F, et al. Preparation of coated zircon sand used for selective laser sintering and study on the forming process of SLS. Foundry, 2017, 66(8): 814-819. (In Chinese)

[46] Xu Z F, Liang P, Yang W, et al. Effects of laser energy density on forming accuracy and tensile strength of selective laser sintering resin coated sands. China Foundry, 2014, 11(3): 151-156.

[47] Cheng R, Wu X Y, Zheng J P. The optimization design study of selective laser sintering process parameters on the pro-coated sand mold. Applied Mechanics and Materials, 2011, 55-57: 853-858.

[48] Liu C Z, Zhang J, Guo C C, et al. Study on curing benzoxazine with phenolic resin and prepared precoated sand. Foundry, 2021, 70(2): 219-224. (In Chinese)

[49] Sun X, Luo Z W, Zhang J Q. Application of SLS technology in investment casting. Plastics Industry, 2019, 47(11): 68-70. (In Chinese)

[50] Gökhan Özer, Burçin Özbay, Zafer Çağatay Öter, et al. Investigation of the surface quality and dimensional accuracy of polymer molds produced by selective laser sintering (SLS) method for investment casting (IC). International Journal of Cast Metals Research, 2020, 33(2-3): 146-152.

[51] Wang D H, Dong A P, Zhu G L, et al. Rapid casting of complex impeller based on 3D printing wax mold and simulation optimization. The International Journal of Advanced Manufacturing Technology, 2019, 100(9-12): 2629-2635.

[52] Shi Y S, Chen J B, Wang Y, et al. Study of the selective laser sintering of polycarbonate and postprocess for parts reinforcement. In: Proceedings of the Institution of Mechanical Engineers, Part L: Journal of Materials: Design and Applications, 2006, 221(1): 37-42.

[53] Shi Y S, Wang Y, Chen J B, et al. Experimental investigation into the selective laser sintering of high-impact polystyrene. Journal of Applied Polymer Science, 2008, 108(1): 535-540.

[54] Yang J S, Shi Y S, Shen Q W, et al. Selective laser sintering of HIPS and investment casting technology. Journal of Materials Processing Technology, 2009, 209(4): 1901-1908.

[55] Yang L X, Bai X, Xu C, et al. Investment casting process of induction wheel based on SLS. Foundry, 2019, 68(10): 11211126. (In Chinese)

[56] Li S S, Xu Z F, Zhao Y Y, et al. Flame retardant mechanism analysis of magnesium alloy for selective laser sintering coated sand mold (core) casting. Foundry, 2015, 64(2): 140-143. (In Chinese) 